\title{
Effect of the film thickness on the effective electron-electron interaction in a metal film
}

\author{
Kostrobij P., Markovych B. \\ Lviv Polytechnic National University, \\ 12 S. Bandera Str., 79013, Lviv, Ukraine
}

(Received 15 June 2018)

\begin{abstract}
An effective electron-electron interaction potential in a metal film is numerically calculated within the jellium model. The effect of the film thickness on this potential is studied and it is found that even minor changes in the film thickness cause significant changes in the behavior of this potential.
\end{abstract}

Keywords: effective interaction, Coulomb interaction, chemical potential, metal film.

2000 MSC: $82 \mathrm{~B} 24$

UDC: 530.145

DOI: $10.23939 / \mathrm{mmc} 2018.01 .021$

\section{Introduction}

Metal films, thickness of which is comparable with the corresponding Fermi wavelength of electrons in it, have physical properties that are different from those of a bulk sample of the same metal $[1,2]$. This difference stimulates intense experimental and theoretical studies of properties of metal films. Density-functional theory, in particular, in the local-density approximation, has been the most widely used method to investigate the properties of metal films. However, the use of local or quasilocal approximations is not justified, because the electron density near the film surface is rapidly varying [3]. Therefore, there is a need to build a consistent quantum statistical theory of such systems. In particular, such theory of the semi-infinite jellium was proposed in Refs. [4-6] and solved the problem of the negative surface energy, which is characteristic of density-functional theory [7]. The central problem of this theory is a calculation of thermodynamic potential and statistical distribution functions of electrons. The use of the functional integration method allows obtaining for them expansions in an effective electron-electron interaction potential. This potential is a solution of the Fredholm integral equation of the second kind and to find it is a difficult problem [8]. In Ref. [8], by using certain approximations, an analytical solution of this integral equation is obtained, which, in particular, depends on a chemical potential of the interacting electron gas in a metal film. A problem of calculating this chemical potential with the correct taking into account the electroneutrality condition is solved in Ref. [6], in which an effect of the film thickness and the Coulomb interaction between electrons on this chemical potential is investigated and it is shown that for the chemical potential there is an oscillatory quantum size effect that disappears with an increase in the film thickness.

In the presented article, using results of Refs. [6,8], we calculate the effective electron-electron interaction potential in the coordinate representation and investigate an effect of the thickness of a metal film, which is considered within the jellium model, on it. It is found that this effect is significant, even a small change in the film thickness leads to a significant change in the effective electron-electron interaction potential, and the change in the film thickness can both amplify and weaken the repulsion between electrons. It is shown that a weak attraction is between a pair of electrons located in the region of a positive charge, and with their removal from this region this attraction disappears, the direct Coulomb repulsion between electrons predominates. 


\section{Model}

As in Ref. [6, 8], we consider a metal film that is located in space so that two unlimited faces are parallel to the plane $x O y$. The film thickness lies along the $z$ axis and is equal to $l_{\text {slab. One of the }}$ faces of the film is located at $z=d$ and the other parallel to it is at $z=l_{\text {slab }}+d$ (see Fig. 1 ).

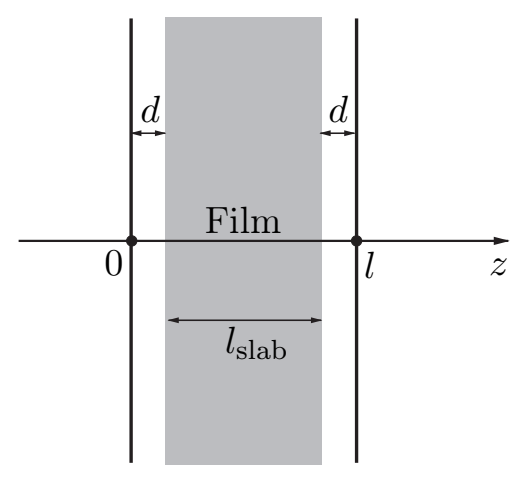

Fig. 1 .

The metal film is considered within the jellium model, i.e. an ion subsystem is replaced by a positive charge with the following distribution

$$
\varrho_{\text {jell }}\left(\mathbf{r}_{\|}, z\right) \equiv \varrho_{\text {jell }}(z)= \begin{cases}\varrho_{0}, & z \in\left[d, l_{\text {slab }}+d\right] \\ 0, & z \notin\left[d, l_{\text {slab }}+d\right]\end{cases}
$$

where $\theta(x)$ is the Heaviside function, $\mathbf{r}_{\|}=(x, y)$, $x, y \in(-\sqrt{S} / 2,+\sqrt{S} / 2), S$ is the area of the face of the metal film $(S \rightarrow \infty), z \in(-\infty,+\infty)$. The electroneutrality condition is satisfied,

$$
\lim _{S \rightarrow \infty} \int_{S} \mathrm{~d} \mathbf{r}_{\|} \int_{-\infty}^{+\infty} \mathrm{d} z \varrho_{\text {jell }}\left(\mathbf{r}_{\|}, z\right)=e N, e>0
$$

moreover, in the thermodynamic limit, we have

$$
\lim _{N, S \rightarrow \infty} \frac{e N}{S l_{\text {slab }}}=\varrho_{0},
$$

where $N$ is the number of electrons, which are situated in the field of the positive charge.

Due to the spatial symmetry of the metal film, the motion of an electron in the plane $x O y$ is free, and along the $z$ axis is determined by a surface potential $V_{\text {surf }}(z)$, which, as in Refs. [6,8], is modeled by the infinite rectangular potential well, i.e.

$$
V_{\text {surf }}(z)=\left\{\begin{array}{cc}
\infty, & z \leqslant 0, z \geqslant l \\
0, & 0<z<l
\end{array}\right.
$$

where $l$ is the parameter of the model potential, which is the width of the infinite rectangular potential well.

This model potential allows analytically to solve the stationary Schrödinger equation,

$$
\left[-\frac{\hbar^{2}}{2 m} \Delta+V_{\text {surf }}(z)\right] \Psi_{\kappa}(\mathbf{r})=E_{\kappa} \Psi_{\kappa}(\mathbf{r}), \quad \mathbf{r}=\left(\mathbf{r}_{\|}, z\right)
$$

with the Dirichlet boundary conditions,

$$
\left.\Psi_{\kappa}(\mathbf{r})\right|_{z=0}=\left.\Psi_{\kappa}(\mathbf{r})\right|_{z=l}=0,
$$

where $m$ is the electron mass, $\kappa=\left(\mathbf{k}_{\|}, \alpha\right), \mathbf{k}_{\| \mid}$is the two-dimensional vector in the $x O y$ plane, $\alpha=\pi n / l$, $n=1,2, \ldots$, i.e. to find the wave functions $\Psi_{\kappa}(\mathbf{r})$ and the corresponding energy levels $E_{\kappa}$ of the electron in the state $\kappa=\left(\mathbf{k}_{\|}, \alpha\right)$ :

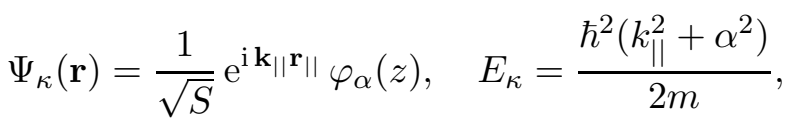

$$
\begin{aligned}
& \varphi_{\alpha}(z)=\left\{\begin{array}{cc}
\sqrt{\frac{2}{l}} \sin (\alpha z), & 0<z<l, \\
0, & z \leqslant 0, z \geqslant l .
\end{array}\right.
\end{aligned}
$$


As we can see from Fig. 1 , there is a relation between the well width $l$ and the film thickness $l_{\text {slab }}$,

$$
l=l_{\text {slab }}+2 d,
$$

where the parameter $d$ is found in Ref. [9],

$$
d=\frac{3 \pi}{8 \mathcal{K}_{\mathrm{F}}}+\frac{\pi^{2}}{8 \mathcal{K}_{\mathrm{F}}^{2} l}
$$

$\mathcal{K}_{\mathrm{F}}=\sqrt{2 m \mu} / \hbar$ is the magnitude of the Fermi wave vector, $\mu$ is the chemical potential with taking into account the Coulomb interaction between electrons.

\section{Numerical results}

In Ref. [8], by using the some approximations, we obtained the following analytical expressions for a two-dimensional Fourier-image of the effective electron-electron interaction potential,

$$
\begin{aligned}
& g^{0}\left(q, z_{1}, z_{2}\right)= \frac{2 \pi e^{2}}{Q} \frac{1}{1-\left(\frac{Q-q}{Q+q}\right)^{2} \mathrm{e}^{-2 Q l}}\left[\mathrm{e}^{-Q\left|z_{1}-z_{2}\right|}+\left(\frac{Q-q}{Q+q}\right)^{2} \mathrm{e}^{-Q\left(2 l-\left|z_{1}-z_{2}\right|\right)}\right. \\
&\left.+\frac{Q-q}{Q+q}\left(\mathrm{e}^{-Q\left(z_{1}+z_{2}\right)}+\mathrm{e}^{-Q\left(2 l-z_{1}-z_{2}\right)}\right)\right], \quad 0 \leqslant z_{1}, z_{2} \leqslant l ; \\
& g^{0}\left(q, z_{1}, z_{2}\right)= \frac{2 \pi e^{2}}{q}\left(\mathrm{e}^{-q\left|z_{1}-z_{2}\right|}-\mathrm{e}^{q\left(z_{1}+z_{2}\right)}\right)+\frac{4 \pi e^{2}}{Q+q} \frac{1+\frac{Q-q}{Q+q} \mathrm{e}^{-2 Q l}}{1-\left(\frac{Q-q}{Q+q}\right)^{2} \mathrm{e}^{-2 Q l}} \mathrm{e}^{q\left(z_{1}+z_{2}\right)}, \quad z_{1}, z_{2} \leqslant 0 \\
& g^{0}\left(q, z_{1}, z_{2}\right)= \frac{2 \pi e^{2}}{q}\left(\mathrm{e}^{-q\left|z_{1}-z_{2}\right|}-\mathrm{e}^{-q\left(z_{1}+z_{2}-2 l\right)}\right) \\
&+\frac{4 \pi e^{2}}{Q+q} \frac{1+\frac{Q-q}{Q+q} \mathrm{e}^{-2 Q l}}{1-\left(\frac{Q-q}{Q+q}\right)^{2} \mathrm{e}^{-2 Q l}} \mathrm{e}^{-q\left(z_{1}+z_{2}-2 l\right)}, \quad l \leqslant z_{1}, z_{2} ; \\
& g^{0}\left(q, z_{1}, z_{2}\right)= \frac{4 \pi e^{2}}{Q+q} \frac{1}{1-\left(\frac{Q-q}{Q+q}\right)^{2} \mathrm{e}^{-2 Q l}}\left[\mathrm{e}^{q z_{1}-Q z_{2}}+\frac{Q-q}{Q+q} \mathrm{e}^{q z_{1}-Q\left(2 l-z_{2}\right)}\right], \quad z_{1} \leqslant 0,0 \leqslant z_{2} \leqslant l ; \\
& \times\left[\mathrm{e}^{-Q\left(l-z_{1}\right)-q\left(z_{2}-l\right)}+\frac{Q}{Q+q} \mathrm{e}^{-Q\left(l+z_{1}\right)-q\left(z_{2}-l\right)}\right], \quad 0 \leqslant z_{1} \leqslant l, l \leqslant z_{2} ; \\
& \times\left[\mathrm{e}^{-q\left(z_{1}-l\right)-Q\left(l-z_{2}\right)}+\frac{Q}{Q+q}-\mathrm{e}^{-q\left(z_{1}-l\right)-Q\left(l+z_{2}\right)}\right], \quad l \leqslant z_{1}, 0 \leqslant z_{2} \leqslant l ; \\
& g^{0}\left(q, z_{1}, z_{2}\right)= \frac{4 \pi e^{2}}{Q+q} \frac{1}{1-\left(\frac{Q-q}{Q+q}\right)^{2} \mathrm{e}^{-2 Q l}} \\
& g^{0}\left(q, z_{1}, z_{2}\right)= \frac{4 \pi e^{2}}{Q+q} \frac{4 \pi e^{2}}{1-\left(\frac{Q-q}{Q+q}\right)^{2} \mathrm{e}^{-2 Q l}} \frac{\frac{2 Q}{Q+q} \mathrm{e}^{-Q l}}{1-\left(\frac{Q-q}{Q+q}\right)^{2} \mathrm{e}^{-2 Q l}} \mathrm{e}^{q z_{1}-q\left(z_{2}-l\right)}, \quad l \leqslant z_{2} ; \\
& g^{0}\left(q, z_{1}, z_{2}\right)=\left.\frac{1}{Q+Q z_{1}+q z_{2}}+\frac{Q-q}{Q+q} \mathrm{e}^{Q\left(z_{1}-2 l\right)+q z_{2}}\right], \quad 0 \leqslant z_{1} \leqslant l, z_{2} \leqslant 0 \\
& \frac{Q-\left(\frac{Q-q}{Q+q}\right)^{2} \mathrm{e}^{-2 Q l}}{Q+q}
\end{aligned}
$$




$$
g^{0}\left(q, z_{1}, z_{2}\right)=\frac{4 \pi e^{2}}{Q+q} \frac{\frac{2 Q}{Q+q} \mathrm{e}^{-Q l}}{1-\left(\frac{Q-q}{Q+q}\right)^{2} \mathrm{e}^{-2 Q l}} \mathrm{e}^{-q\left(z_{1}-l\right)+q z_{2}}, \quad l \leqslant z_{1}, z_{2} \leqslant 0
$$

where $Q^{2}=q^{2}+\varkappa^{2}(q), \varkappa^{2}(q)=4 \pi e^{2} \frac{2 m}{\hbar^{2}} \frac{1}{2 \pi l} \sum_{\alpha}\left[1-\sqrt{1-4 \frac{\mathcal{K}_{\mathrm{F}}^{2}-\alpha^{2}}{q^{2}}} \theta\left(1-4 \frac{\mathcal{K}_{\mathrm{F}}^{2}-\alpha^{2}}{q^{2}}\right)\right] \theta\left(\mathcal{K}_{\mathrm{F}}-\alpha\right)$.

By using the two-dimensional Fourier-image of the effective electron-electron interaction potential $g^{0}\left(q, z_{1}, z_{2}\right)$ and the Fourier transform, we obtain the effective electron-electron interaction potential in the coordinate representation,

$$
g^{0}\left(r_{\|}, z_{1}, z_{2}\right)=\frac{1}{2 \pi} \int_{0}^{\infty} \mathrm{d} q q \mathrm{~J}_{0}\left(q r_{\|}\right) g^{0}\left(q, z_{1}, z_{2}\right),
$$

where $r_{\|}$is the distance between electrons in the plane of the metal film, $\mathrm{J}_{0}(x)$ is the cylindrical Bessel function of zero order. Further calculation according to Eq. (17) must be performed numerically, using values of the chemical potential, which were found in Ref. [6].

In Figs. 2, 3, the results of numerical calculations are given according to Eqs. (8)-(16) and (17) for different film thicknesses and the Wigner-Seitz radius $r_{\mathrm{s}}=2 a_{\mathrm{B}}$.
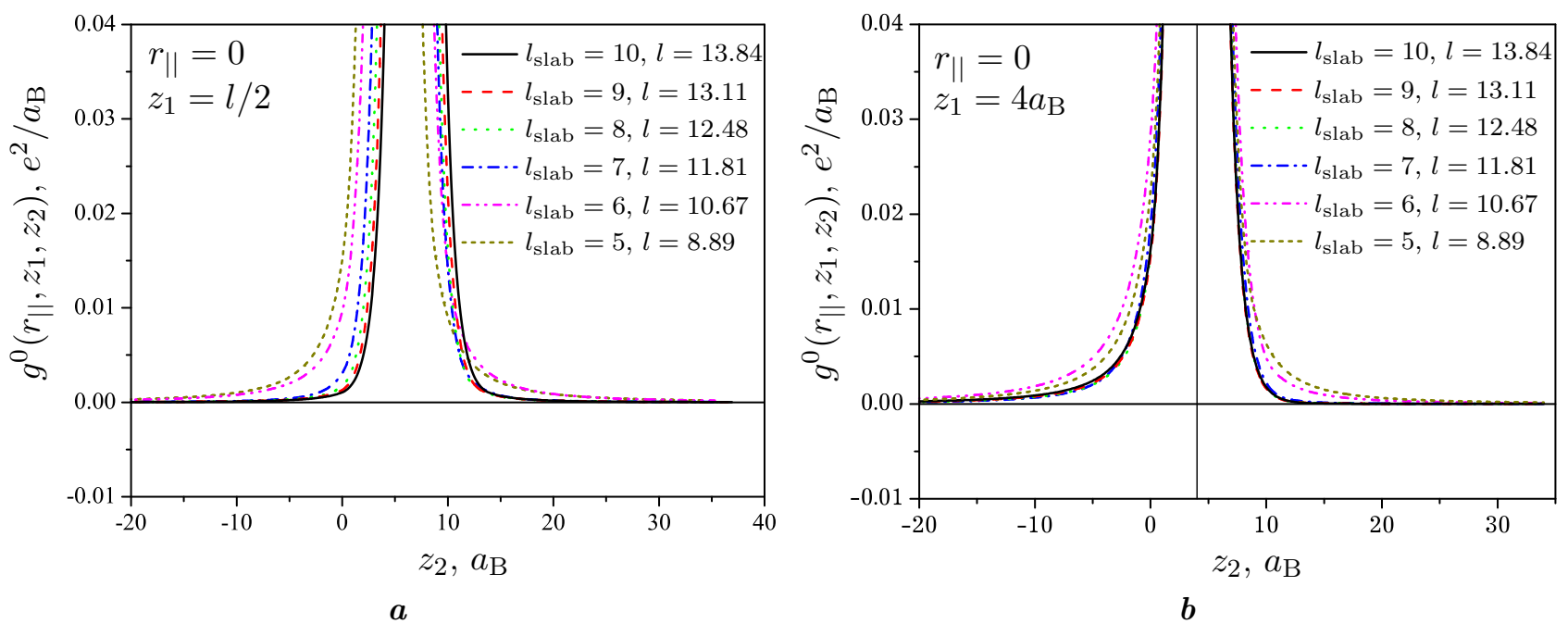

Fig. 2. Dependence of the effective electron-electron interaction potential from the normal to the film faces coordinate of one of two electrons, the other is fixed, the distance between two electrons in the film plane is zero (the parameters $l$ and $l_{\text {slab }}$ are given in units of $a_{\mathrm{B}}$ ).

In Fig. $2 a$, there is shown the effective electron-electron interaction potential as function of the normal to the film plane coordinate of one of two electrons, the other is in the film middle and the distance between electrons in the film plane is zero. Calculations are made for the different film thicknesses. From this figure it is clear that this potential is symmetric with respect to the film center. If the film thickness decreases, repulsion between two electrons becomes stronger as a result of the fact that the thin film has fewer electrons and, accordingly, screening of the direct Coulomb interaction is weaker, i.e. screening of the direct Coulomb repulsion in thin film is weaker than in thick film.

In Fig. $2 b$, there is also shown the effective electron-electron interaction potential as function of the normal to the film plane coordinate of one electron, the other is fixed at the point $z_{1}=4 a_{\mathrm{B}}$, the distance between electrons in the film plane is equal to zero. Calculations are made for the different film thicknesses. Due to the fact that the normal to the film plane coordinate of one of two electrons is not fixed in the film center, this dependence is non-symmetrical. More electrons is to the right of the fixed electron than to the left, so screening in the domain $z_{2}>4 a_{\mathrm{B}}$ is stronger than in the domain 
$z_{2}<4 a_{\mathrm{B}}$. As a result, the effective potential approaches faster to zero in the domain $z_{2}>4 a_{\mathrm{B}}$ than in the domain $z_{2}<4 a_{\mathrm{B}}$.
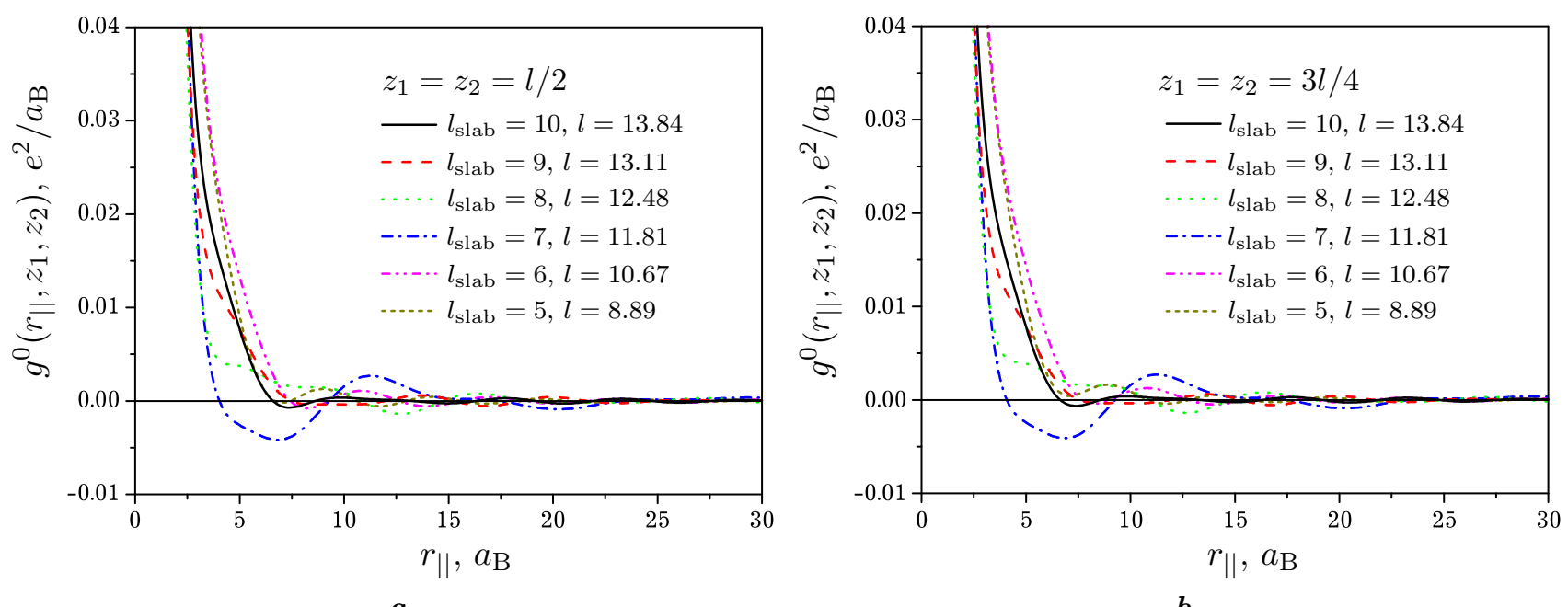

$a$
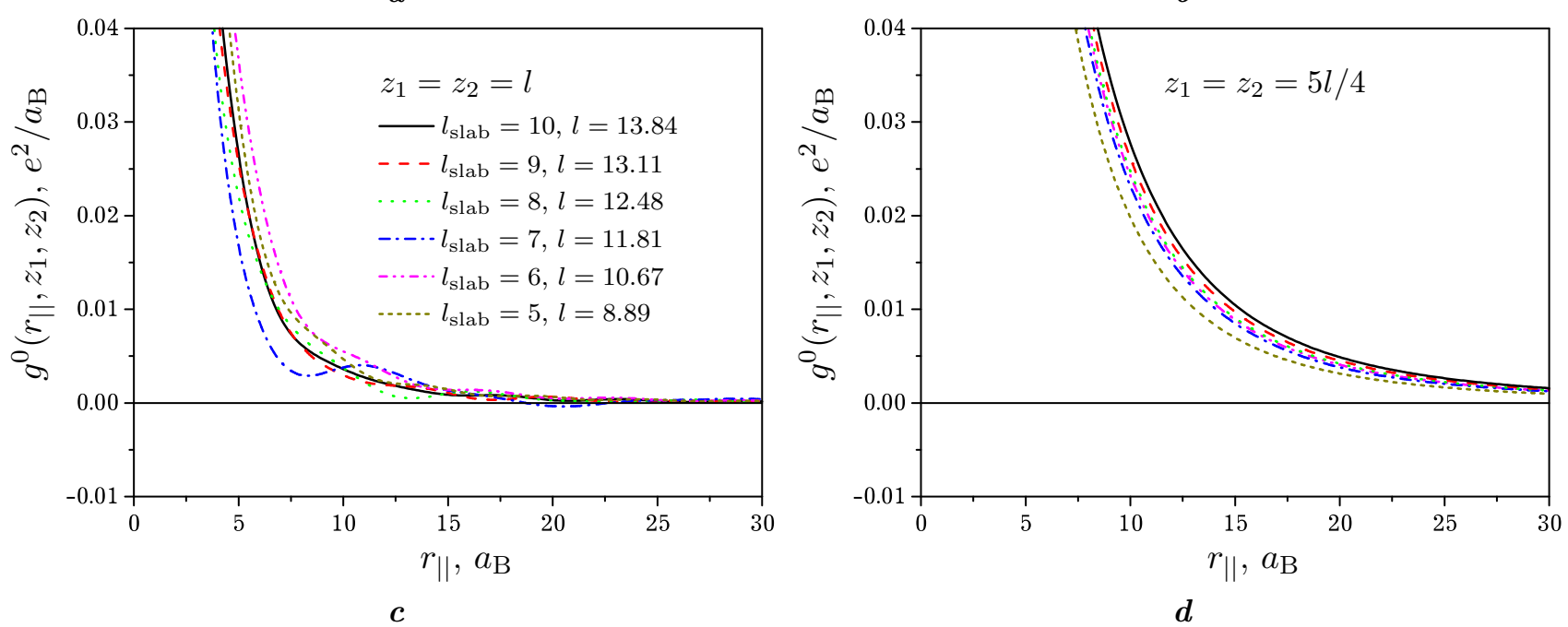

Fig. 3. Dependence of the effective electron-electron interaction potential from the distance between two electrons in the film plane, the normal to the film plane coordinates of two electrons are fixed (the parameters $l$ and $l_{\text {slab }}$ are given in units of $a_{\mathrm{B}}$ ).

In Fig. 3, there is shown the effective electron-electron interaction potential as function of the distance between electrons in the film plane for the different film thicknesses, two electrons are: in the middle of the metal film $(a)$, at the distance of a quarter of the well width to the infinite rectangular potential wall $(b)$, on the edge of the infinite rectangular potential wall $(c)$, and outside the metal film at a distance of a quarter of the well width from the edge of the infinite rectangular potential wall $(d)$. From these figures we can see that if the thickness of the film increases, the effective electron -electron interaction potential approaches to that which is in the semi-infinite jellium model $[10,11]$, i.e. there are domains of electron coordinates in which this effective potential is attractive. If the film thickness decreases, there is a nonmonotonic behavior of this potential: the effective attraction between two electrons either amplifies, or weakens. In particular, in the metal film of thickness $l_{\text {slab }}=7 a_{\mathrm{B}}$, the effective attraction between electrons is the strongest, whereas for films with thicknesses $6 a_{\mathrm{B}}$ and $8 a_{\mathrm{B}}$ the effective attraction is significantly smaller. This behavior of the effective electron-electron interaction potential is due to the fact that the chemical potential of the electrons in the metal film is an oscillating function of the film thickness. 


\title{
4. Conclusions
}

The effective electron-electron interaction potential is calculated numerically in the coordinate representation. It is shown that depending on the film thickness there is observed either enhancement of the screening of the direct Coulomb interaction, or its weakening. This is the result of an oscillatory quantum-size effect for the chemical potential. It is shown that with an increase in the film thickness, the effective electron-electron interaction potential approaches to one that is in the semi-infinite jellium model.

[1] Cohen M. L., Knight W. D. The Physics of Metal Clusters. Phys. Today. 43 (12), 42-50 (1990).

[2] de Heer W. A. The physics of simple metal clusters: experimental aspects and simple models. Rev. Mod. Phys. 65 (3), 611-676 (1993).

[3] Pitarke J. M., Eguiluz A. G. Jellium surface energy beyond the local-density approximation: Self-consistentfield calculations. Phys. Rev. B. 63 (4), 045116 (2001).

[4] Kostrobij P. P., Markovych B. M. Semi-infinite jellium: Thermodynamic potential, chemical potential, and surface energy. Phys. Rev. B. 92 (7), 075441 (2015).

[5] Kostrobij P. P., Markovych B. M. Semi-infinite jellium: Step potential model. Phys. Rev. B. 93 (15), 155401 (2016).

[6] Kostrobij P. P., Markovych B. M. Effect of Coulomb interaction on chemical potential of metal film. Philosophical Magazine. 98 (21), 1991-2002 (2018).

[7] Lang N. D., Kohn W. Theory of Metal Surfaces: Charge Density and Surface Energy. Phys. Rev. B. 1 (12), 4555-4568 (1970).

[8] Kostrobij P., Markovych B. Effective inter-electron interaction for metallic slab. Mathematical Modeling and Computing. 3 (1), 51-58 (2016).

[9] van Himbergen J. E., Silbey R. Exact solution of metal surface properties in square barrier and linear one-electron potential models. Phys. Rev. B. 18 (6), 2674-2682 (1978).

[10] Kostrobij P.P., Markovych B. M. An effective potential of electron-electron interaction in semi-infinite jellium. Condensed Matter Physics. 9 (4), 747-756 (2006).

[11] Markovych B. M., Zadvorniak I. M. Effective potential of electron-electron interaction in the semiinfinite electron gas with regard for the local-field correction. Ukr. J. Phys. 59 (11), 1107-1113 (2014).

\section{Вплив товщини плівки на ефективну міжелектронну взаємодію в металевій плівці}

\author{
Костробій П., Маркович Б. \\ Національний університет «Львівсъка політехніка», \\ вул. С. Бандери, 12, Лъвів, 79013
}

\begin{abstract}
Чисельно розраховано ефективний потенціал міжелектронної взаємодії в металевій плівці, яку розглядають у межах моделі «желе». Досліджено вплив товщини плівки на цей потенціал та виявлено, що навіть незначні зміни товщини плівки спричинюють суттєві зміни поведінки цього потенціалу.
\end{abstract}

Ключові слова: ефективна взаемодія, кулонівсъка взаємодія, хімічний потенціал, металева плівка.

2000 MSC: $82 \mathrm{~B} 24$

УдК: 530.145

Mathematical Modeling and Computing, Vol.5, No. 1, pp. 21-26 (2018) 